\title{
Non-equilibrium Phases Formed in Cu-In-Se-Te System Synthesized by Melt-Quench Method
}

\author{
Rangasami Chinnusamy
}

Received: 31 July 2014/Revised: 28 October 2014/Published online: 15 February 2015

(C) The Chinese Society for Metals and Springer-Verlag Berlin Heidelberg 2015

\begin{abstract}
Non-equilibrium phases formed in melt-quenched $\mathrm{CuIn}\left(\mathrm{Se}_{x} \mathrm{Te}_{1-x}\right)_{2}$ system, where $x=0.1,0.2,0.4,0.5,0.6$, 0.8 and 0.9 , have been studied using Rietveld refinement of the crystal structure and Raman spectroscopy. Results of structure refinement have showed that all the samples, except the $\mathrm{CuIn}\left(\mathrm{Se}_{0.1} \mathrm{Te}_{0.9}\right)_{2}$, are heterogeneous. All the observed non-equilibrium phases are quaternary system and are found to have chalcopyrite structure $(I \overline{4} 2 d)$, in accordance with the $\mathrm{CuInTe}_{2}-\mathrm{CuInSe}_{2}$ phase diagram. The lattice constants deduced from the refinement have showed linear variation with $\mathrm{Se}$ content. A detailed analysis of the characteristic $A_{1}$ modes present in the Raman spectrum of individual sample has corroborated the results obtained from the structure analysis. The position of $A_{1}$ mode of individual phase is found to vary linearly with Se content, which suggests that $\mathrm{CuIn}\left(\mathrm{Se}_{x} \mathrm{Te}_{1-x}\right)_{2}$ system exhibits single-mode behaviour.
\end{abstract}

\section{KEY WORDS: Chalcogenides; Crystal growth; Phase coexistence; X-ray diffraction; Crystal structure; Raman spectroscopy}

\section{Introduction}

I-III-VI - -based chalcopyrites have been studied extensively due to their technological importance $[1,2]$. These chalcopyrites are direct band gap semiconductors with large absorption coefficient $\left(>10^{5} \mathrm{~cm}^{-1}\right)$ in the near-infrared region and find potential applications in photovoltaics and nonlinear optics. For instance, $\mathrm{CuInSe}_{2}$ (band gap $\sim 1 \mathrm{eV}$ ) thin film-based solar cells with efficiency of 19.6\% have been demonstrated (http://www.pv-tech.org). $\mathrm{AgGaSe}_{2}$ exhibits large nonlinear optical coefficient $(\sim 33 \mathrm{pm} / \mathrm{V}$ at $10.6 \mu \mathrm{m})$ and high transmission in the infrared region [3, 4]. In fact, $\mathrm{AgGaSe}_{2}$ crystals for second

Available online at http://link.springer.com/journal/40195

R. Chinnusamy $(\bowtie)$

Department of Physics, Kongu Engineering College, Perundurai, Erode 638052, Tamil Nadu, India

e-mail: kkaumaran@gmail.com harmonic generation are commercially available (http:// www.ekspla.com).

Solid solutions of I-III-VI ${ }_{2}$-based chalcopyrite semiconductors with suitable elemental proportions exhibit a wide range of lattice constants and optical band gaps. Application wise, solid solutions of this kind have been investigated intensively for high-efficiency solar cells. For example, conversion efficiency of $20.3 \%$ has been achieved with $\mathrm{CuIn}_{p} \mathrm{Ga}_{1-p} \mathrm{Se}_{2}$ (band gap $\sim 1.2 \mathrm{eV}$ )-based solar cells [5]. $\mathrm{CuIn}_{p} \mathrm{Al}_{1-p} \mathrm{Se}_{2}$ shows conversion efficiency of $16.9 \%$ [6]. Efficiency of $7.3 \%$ has been reported for a tandem solar cell with $\mathrm{AgInGaSe}$ as absorber layer [7]. Similarly, $\mathrm{CuIn}\left(\mathrm{S}_{p} \mathrm{Se}_{1-p}\right)_{2}$ has also been studied fairly well for solar cell applications [8]. Moreover, $\mathrm{Ag}_{p} \mathrm{Cu}_{1-p} \mathrm{GaS}_{2}$ exhibits Ag-dependent optical nonlinear behaviour [9].

$\mathrm{CuInSeTe}$, solid solution of CuInSe $\mathrm{C}_{2}$ and $\mathrm{CuInTe}_{2}$, exhibits p-type conductivity, in general, and it can be changed into n-type by thermal treatment. CuInSeTe thin films show the presence of several energy gaps from 0.86 to $1.71 \mathrm{eV}$, which vary with $\mathrm{Cu} / \mathrm{Te}$ and $\mathrm{Cu} / \mathrm{Se}$ ratios. Depending on the growth conditions adopted, the resistivity and mobility of 
the film are found to vary in the ranges of $10^{-3}$ to $8 \Omega \mathrm{cm}$, and 0.2 to $28.6 \mathrm{~cm}^{2} \mathrm{~V}^{-1} \mathrm{~s}^{-1}$, respectively. Based on these observations, it has been suggested that CuInSeTe can be a suitable material to form heterojunction photovoltaic cells with good interface matching [10]. Herberholz and Carter [11] have fabricated solar cell using graded $\mathrm{CuInSe}_{2} /$ $\mathrm{CuInTe}_{2}$ films as an absorber with chemical bath-deposited $\mathrm{CdS}$ and sputtered $\mathrm{ZnO}$ films. The device characteristics are found to be comparable to that of the devices formed with $\mathrm{CuInSe}_{2}$. Bodnar et al. [12] have studied optical properties and structural state of nanoparticles of $\mathrm{CuIn}\left(\mathrm{Se}_{p} \mathrm{Te}_{1-p}\right)_{2}$ embedded in a silicate glass matrix. The samples have been formed by high-temperature melting of the parent compounds and glass-forming components together. Particle sizes are found to be in the range of 15-30 $\mathrm{nm}$. From the optical absorption study, they found that the crystalline structure of nanoparticles changes from chalcopyrite to zinc blende structure with Se to Te ratio.

Most of the I-III-VI - -based solid solutions have been synthesized from melt by quenching or slow cooling, with an aim to form equilibrium phases. Except few systems such as $\left(\mathrm{Ag}_{p} \mathrm{Cu}_{1-p}\right)-\mathrm{Al} / \mathrm{Ga}-(\mathrm{S} / \mathrm{Se})_{2}$ and $\mathrm{I}-\mathrm{III}-\left(\mathrm{S}_{p} \mathrm{Te}_{1-p}\right)_{2}$ [13, 14], all others exhibit complete solubility for the whole range of substitution. Among these solid solutions, synthesis of single-phase anion-substituted ones requires annealing for long period of about 5 months in the temperature range of $873-1073 \mathrm{~K}$. The examples include $\mathrm{CuIn}\left(\mathrm{Se}_{p} \mathrm{Te}_{1-p}\right)_{2}$, $\mathrm{AgGa}\left(\mathrm{Se}_{p} \mathrm{Te}_{1-p}\right)_{2}$ and $\mathrm{CuGa}\left(\mathrm{Se}_{p} \mathrm{Te}_{1-p}\right)_{2}$ [14-16]. The requirement of heat treatment for extremely long duration indicates that melt-quench method does not provide sufficient time for the anion-substituted systems to equilibrate. Therefore, non-equilibrium phases will prevail, and the interest here is to identify and investigate the phases formed in melt-quenched $\mathrm{CuIn}\left(\mathrm{Se}_{x} \mathrm{Te}_{1-x}\right)_{2}$ system using Rietveld refinement of crystal structure and Raman spectroscopy.

\section{Experimental}

\subsection{Synthesis of $\mathrm{CuIn}\left(\mathrm{Se}_{x} \mathrm{Te}_{1-x}\right)_{2}$}

Polycrystalline $\mathrm{CuIn}\left(\mathrm{Se}_{x} \mathrm{Te}_{1-x}\right)_{2}$, where $x=0.1,0.2,0.4$, $0.5,0.6,0.8$ and 0.9 , was formed by melt-quench method. Briefly, $5 \mathrm{~N}$ purity $\mathrm{Cu}$, In, Se and Te pieces with suitable compositional ratio and total mass of $\sim 5 \mathrm{~g}$ were taken in a cleaned quartz ampoule. The ampoule was then evacuated to a pressure of $\sim 5 \times 10^{-6}$ mbar and sealed with the charge inside. The sealed ampoule was heated in a vertical tubular furnace, the temperature of which was controlled to an accuracy of $\pm 2 \mathrm{~K}$. The furnace temperature was initially increased to $523 \mathrm{~K}$ at a rate of $4 \mathrm{~K} / \mathrm{min}$ and was maintained at this temperature for $3 \mathrm{~h}$ in order to allow the exothermic reaction to take place between In and $\mathrm{Se} / \mathrm{Te}$ at a controlled rate [17]. Heating was continued at the same rate of $4 \mathrm{~K} / \mathrm{min}$ up to $1323 \mathrm{~K}$, which is higher than the melting point of any of the constituent elements. The charge in the ampoule was allowed to react in this molten state for $60 \mathrm{~h}$ with intermittent shaking in order to improve the homogeneity. Finally, the ampoule with the charge inside was quenched in water. The ingot thus obtained was polycrystalline and was black in colour with shiny surface. Figure 1 shows the block diagram of thermal cycle followed in meltquench method.

\subsection{Characterization of $\mathrm{CuIn}\left(\mathrm{Se}_{x} \mathrm{Te}_{1-x}\right)_{2}$}

\subsubsection{Rietveld Analysis}

Powder X-ray diffraction data of $\mathrm{CuIn}\left(\mathrm{Se}_{x} \mathrm{Te}_{1-x}\right)_{2}$ system were recorded in the $2 \theta$ range of $10^{\circ}-130^{\circ}$ with step size of $0.017^{\circ}$ using PANalytical XRD (model X'Pert PRO) provided with $\mathrm{Cu} K_{\alpha}$ radiation at room temperature. Rietveld refinements were carried out using General Structure Analysis System (GSAS) software supported by EXPGUI graphical user interface, which allows simultaneous refinement of two wavelengths, $K_{\alpha 1}$ and $K_{\alpha 2}$ with intensity ratio of 0.5 [18]. Shifted Chebyschev polynomial was used to describe the background, and a Pseudo-Voigt profile function was used to model the peak shapes. The quality of fit was described by the discrepancy factors $R_{\mathrm{p}}, R_{\mathrm{wp}}, R_{\mathrm{exp}}$, $R_{\mathrm{F}}, \chi^{2}$ and the goodness of fit (GOF) [19].

\subsubsection{Micro-Raman Measurements}

Micro-Raman measurements were carried out in backscattering geometry using Horiba Jobin-Yvon Raman spectrometer, model LABRAM with 1800 grooves per

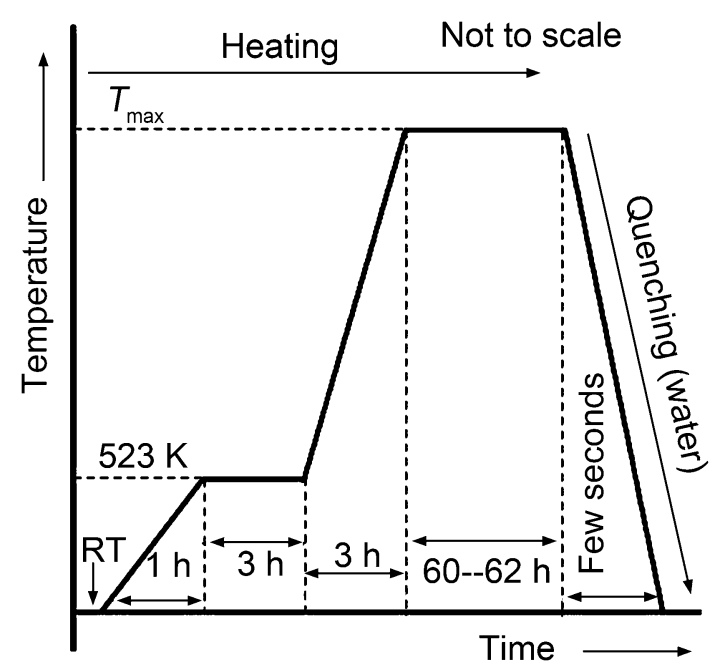

Fig. 1 Schematic diagram of thermal cycle followed in melt-quench $\operatorname{method}\left(T_{\max }=1323 \mathrm{~K}\right)$ 
millimetre grating (resolution $=0.3 \mathrm{~cm}^{-1}$ ) at room temperature. An argon-ion laser with 488-nm plane-polarized beam was used as the excitation source. Raman spectra were recorded with the laser beam power of $1 \mathrm{~mW}$ focused to a spot size of $\sim 2 \mu \mathrm{m}$. Measurements were made on the shiny surface of small pieces obtained from the ingot.

\section{Result and Discussion}

\subsection{Phase Homogeneity of $\mathrm{CuIn}\left(\mathrm{Se}_{x} \mathrm{Te}_{1-x}\right)_{2}$}

Powder XRD spectra of $\mathrm{CuIn}\left(\mathrm{Se}_{x} \mathrm{Te}_{1-x}\right)_{2}$ system, where $x=0.1,0.2,0.4,0.6,0.8$ and 0.9 , recorded in the $2 \theta$ range of $24^{\circ}-27^{\circ}$ in which the highest intensity reflection is present are shown in Fig. 2. From Fig. 2a, it is observed that the sample with initial composition $x=0.1$ exhibits symmetric highest intensity peak at $2 \theta=25.125^{\circ}$. Since

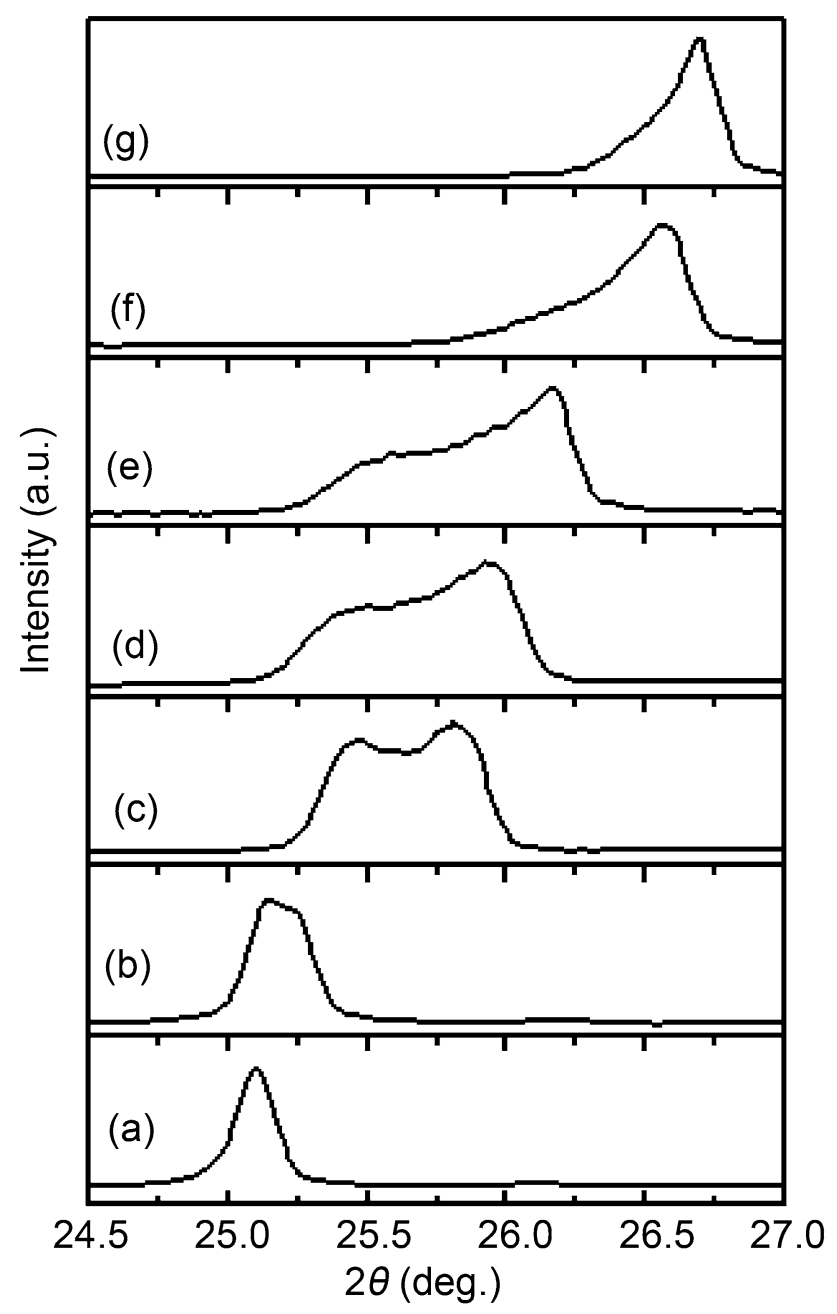

Fig. 2 XRD patterns of $\mathrm{CuIn}\left(\mathrm{Se}_{x} \mathrm{Te}_{1-x}\right)_{2}$ system in the $2 \theta$ range 24.5-27.0: a $x=0.1$, b $x=0.2$, c $x=0.4$, d $x=0.5$, e $x=0.6$, f $x=0.8, \mathbf{g} x=0.9$
CuInSeTe compound has been reported to crystallize in tetragonal chalcopyrite structure with space group $I \overline{4} 2 d$ [20], it is assumed that all $\mathrm{CuIn}\left(\mathrm{Se}_{x} \mathrm{Te}_{1-x}\right)_{2}$ compounds can crystallize in the same structure. As an encouraging observation, all the reflections observed in the XRD pattern of the sample with initial composition $x=0.1$ are found to obey the extinction conditions of the space group $I \overline{4} 2 d$. This observation reveals clearly that the sample is formed as an equilibrium (single) phase. On the other hand, the samples with initial composition $x=0.2$ onwards were observed to exhibit two peaks or peak broadening within the $2 \theta$ range mentioned above. For instance, the powder diffraction data of the sample prepared with initial composition of $\mathrm{CuIn}\left(\mathrm{Se}_{0.2} \mathrm{Te}_{0.8}\right)_{2}$ (Fig. 2b) show clearly two closely spaced peaks. This is in contrast with what was observed for $\mathrm{CuIn}\left(\mathrm{Se}_{0.1} \mathrm{Te}_{0.9}\right)_{2}$, wherein a single peak is present. Further, when viewed on a magnified scale, two closely spaced peaks were easily noticeable in all the observed reflections in the experimental diffraction data. Splitting of peaks may be due to existence of multiple phases or microstrain or both. It is a known fact that microstrain can affect the shape of reflections in the diffraction pattern. However, microstrain is direction dependent, and therefore, it will not be reflected uniformly in all crystallographic directions, which means that there cannot be uniform splitting of all the reflections in the diffraction data. Thus, there may be strain due to difference in ionic radii of $\mathrm{Te}$ and $\mathrm{Se}$, but the dominating factor responsible for the splitting of reflections may be the presence of secondary phases.

The diffraction pattern of the sample with $x=0.4$ shown in Fig. 2c exhibits two closely spaced peaks. This observation reveals that $\mathrm{CuIn}\left(\mathrm{Se}_{0.4} \mathrm{Te}_{0.6}\right)_{2}$ may also be a heterogeneous mixture of two phases, and the angular separation between the two peaks is quite large compared to the previous one. Differently, the samples with initial composition $x=0.5,0.6,0.8$ and 0.9 are found to exhibit peak broadening, and the peak broadening increases up to $x=0.6$ and then decreases. In order to identify the phase homogeneity and crystal structure, Rietveld refinement of crystal structure of $\mathrm{CuIn}\left(\mathrm{Se}_{x} \mathrm{Te}_{1-x}\right)_{2} \quad$ system, where $x=0.1,0.2,0.4,0.5,0.6,0.8$ and 0.9 , was carried out and the results are presented.

\subsection{Structure Refinement}

Rietveld refinements were initiated with the space group $I \overline{4} 2 d$, as the parent compounds $\mathrm{CuInSe}_{2}$ and $\mathrm{CuInTe}_{2}$ crystallize with the same space group. In $I \overline{4} 2 d$ unit cell, $\mathrm{Cu}$ atoms occupy $4 \mathrm{a}$ at $(0,0,0)$, In atoms occupy $4 \mathrm{~b}$ at $(0,0$, $1 / 2)$, and Se and Te atoms occupy $8 \mathrm{~d}$ at $(X, 1 / 4,1 / 8)$, where $X$ is a free parameter [21, 22]. The following assumptions 
were used as constraints for the refinements. Anion sublattice (site 8d) is statistically shared by Se and Te atoms as both of them having similar thermal and displacement parameters. Initial site occupancies were assigned based on the starting compositional ratio of constituent elements, specific to a particular sample.

\subsection{1 $\mathrm{CuIn}\left(\mathrm{Se}_{0.1} \mathrm{Te}_{0.9}\right)_{2}$}

Rietveld refinement of crystal structure of $\mathrm{CuIn}\left(\mathrm{Se}_{0.1} \mathrm{Te}_{0.9}\right)_{2}$ converged satisfactorily to $R_{\mathrm{wp}}=5.19 \%$ (GOF: 2.983). The results of refinement are presented in Fig. 3 along with the experimental data. In Fig. 3, the symbols (crosses) denote observed data, grey line through the data points represents calculated data, vertical lines correspond to possible Bragg reflections, and the bottom curve denotes the difference between the experimental and calculated data. The insets $b$ and c show, on an expanded scale, the 112 reflection and the spectrum in the $2 \theta$ range from $80^{\circ}$ to $130^{\circ}$, respectively. The inset $\mathrm{b}$ shows clearly that the calculated data follows the observed data well in the higher angular region. The results of refinement revealed that $\mathrm{CuIn}\left(\mathrm{Se}_{0.1} \mathrm{Te}_{0.9}\right)_{2}$ is a homogeneous quaternary phase with chalcopyrite structure (space group: $I \overline{4} 2 d$ ). From Fig. $3 \mathrm{a}$ and b, the 112 peak is observed to be a symmetric and most intense one $\left(2 \theta=25.125^{\circ}\right.$, structure factor: $\left.4 f_{\mathrm{cu}}+4 f_{\mathrm{In}}-8 i f_{\mathrm{Se} / \mathrm{Te}}\right)$. In fact, it is reported as the highest intensity reflection among all allowed reflections for the chalcopyrite structure. All the observed reflections can be categorized as reflections from typical zinc blende lattice ( $h+k+l=2 n$ and even 1-indices) and chalcopyrite lattice ( $h+k+l=2 n$ and odd l-indices). The unit cell of $\mathrm{CuIn}\left(\mathrm{Se}_{0.1} \mathrm{Te}_{0.9}\right)_{2}$ has two different tetrahedral arrangements with anions as central atoms. In the first, Te is assumed to be the central atom and is tetrahedrally bonded to two $\mathrm{Cu}$ and two In atoms, while in the other, Te atom is replaced by Se atom without disturbing the cations. The average lattice parameters obtained from the Rietveld refinement are as follows: $a=6.15703(26) \AA$ and $c=12.34222(65) \AA$, which gives rise to a tetragonal distortion $(c / 2 a)$ of 0.9972 . It is worth mentioning that although there is a large mismatch between the ionic radii of the anions (radii of $\mathrm{Te}^{2-}$ and $\mathrm{Se}^{2-}$ are 2.11 and $1.91 \AA$ ), $\mathrm{CuIn}\left(\mathrm{Se}_{0.1} \mathrm{Te}_{0.9}\right)_{2}$ exhibits single-phase nature without any secondary, ternary or elemental phases. Miller indices of some of the reflections observed in the XRD pattern are listed in Table 1. For the sake of brevity, not all the reflections were included but only those which satisfy the following criteria were considered. For reflections from zinc blende lattice, reflections with a nominal relative intensity of $3 \%$ or more were taken. For reflections specific to chalcopyrite lattice, the minimum relative intensity chosen was $1.5 \%$, as these reflections were always less in intensity compared to those from zinc blende lattice. In addition, (101) reflection, though it has intensity lower than the set minimum value (1.5\%), was also included as it is the first reflection with largest $d$ value.

\subsection{2 $\mathrm{CuIn}\left(\mathrm{Se}_{x} \mathrm{Te}_{1-x}\right)_{2}$}

Rietveld refinement of crystal structure of the other samples $(x=0.2-0.9)$ which are expected to be heterogeneous was carried out as per the procedure described below. First, it was assumed that a particular sample was mixture of multiple phases. Second, all the phases were taken to be quaternary (chalcopyrite with space group $I \overline{4} 2 d$ ) with different $\mathrm{Te}$ and $\mathrm{Se}$ concentration. Then, the angular positions corresponding to the highest intensity reflection 112 and the next high intensity reflection 204 were found out using the software X'Pert HighScore Plus. Using these data, the corresponding $d$ spacing and hence the lattice constants

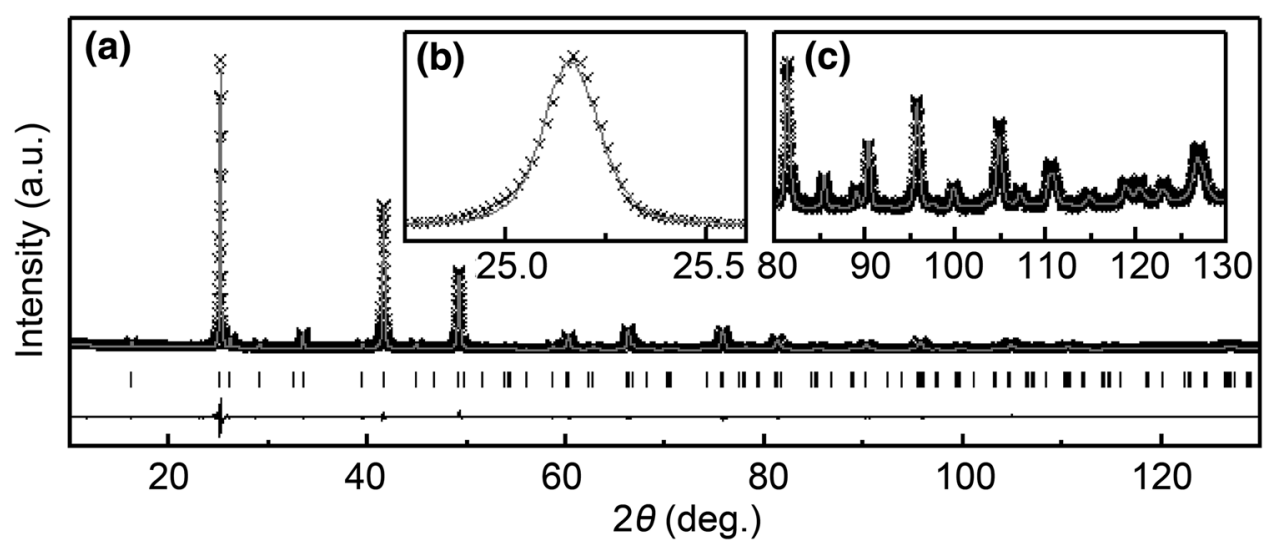

Fig. 3 a XRD pattern and the results of Rietveld refinement for $\mathrm{CuIn}\left(\mathrm{Se}_{0.1} \mathrm{Te}_{0.9}\right)$, the crosses and the overlying solid line represent the experimental data and the calculated profile, respectively, and the short vertical markers indicate possible Bragg reflections, whereas the bottom curve denotes the difference between the experimental and calculated data, $\mathbf{b}$ inset shows the enlarged view of 112 reflection, $\mathbf{c}$ inset shows the spectrum in the $2 \theta$ range of $80^{\circ}-130^{\circ}$, on an expanded scale 
Table 1 Calculated lattice spacing $\left(d_{\text {cal }}\right)$, relative intensity $\left(I_{\text {cal }}\right)$ and Miller indices of selected reflections of $\mathrm{CuIn}\left(\mathrm{Se}_{0.1} \mathrm{Te}_{0.9}\right)_{2}$

\begin{tabular}{lrr}
\hline$h k l$ & $d_{\text {cal }}(\AA)$ & $I_{\text {cal }}(\%)$ \\
\hline 101 & 5.5095 & 1.1 \\
112 & 3.5575 & 100.0 \\
103 & 3.4207 & 4.3 \\
211 & 2.6874 & 6.0 \\
204 & 2.1793 & 47.6 \\
220 & 2.1768 & 23.0 \\
301 & 2.0245 & 2.3 \\
116 & 1.8599 & 15.2 \\
312 & 1.8568 & 28.2 \\
323 & 1.5772 & 2.4 \\
008 & 1.5428 & 3.9 \\
400 & 1.5393 & 6.2 \\
316 & 1.4141 & 9.6 \\
332 & 1.4127 & 4.4 \\
325 & 1.4044 & 1.6 \\
228 & 1.2587 & 5.9 \\
424 & 1.2573 & 10.5 \\
512 & 1.1850 & 4.3 \\
408 & 1.0424 & 3.1 \\
\hline & &
\end{tabular}

were calculated for the quaternary phases. Assuming that the lattice constants vary linearly with composition throughout the range, an estimate of the composition for a given set of lattice constants ( $a$ or $c$ ) can be obtained from the lattice constants of the end compounds reported in JCPDS. In the present case, the equation $a=6.2190-$ $0.4370 x$, where $x$ is the composition of Se is used. These lattice constants and the corresponding phases were used as part of the initial parameters for the refinement of the crystal structure. For the sake of brevity, the results of detailed analysis of phase homogeneity and crystal structure of the sample with initial composition $x=0.5$ alone are presented here as representative for all other heterogeneous samples.

Experimental diffraction pattern of the sample synthesized with Se content of $x=0.5$ is shown Fig. 2d. The pattern shows two peaks clearly similar to the observations made on samples with Se content of $x=0.2$ and 0.4. However, the angular separation between the peaks is quite large $\left(\sim 1.2^{\circ}\right)$ compared to those of previous two samples. A quick analysis with X'pert HighScore Plus revealed an additional third peak in between the two outer peaks that are visible to naked eye. For instance, three 112 reflections were found to occur at $2 \theta$ of $25.533^{\circ}, 25.804^{\circ}$ and $26.025^{\circ}$ as shown in Fig. 2d. The appearance of the three peaks has been taken as an indicator to the existence of three quaternary phases with different anion contents. Initial analysis using these three angular positions and the corresponding
204 reflections, as discussed previously, yielded the lattice constants and the Se content $(x)$ of the three phases to be: $a=6.042 \AA$ and $c=12.081 \AA$ for $x=0.41 ; a=$ $6.002 \AA$ and $c=11.870 \AA$ for $x=0.50 ; a=5.954 \AA$ and $c=11.764 \AA$ for $x=0.61$. These values formed part of the some of the parameters needed for initiating the Rietveld refinement of the crystal structure of $\operatorname{CuIn}\left(\mathrm{Se}_{x} \mathrm{Te}_{1-x}\right)_{2}$ with $x=0.5$. The refinement converged satisfactorily to $R_{\mathrm{wp}}=3.89 \%$ (GOF: 1.070 ).

Figure 4 shows the experimental diffraction pattern and the results of refinement of the crystal structure of the $\mathrm{CuIn}$ $\left(\mathrm{Se}_{x} \mathrm{Te}_{1-x}\right)_{2}$ with $x=0.5$. The insets given in Fig. 4 carry the same meaning as those of the Fig. 3. The phases identified from the refinement results are $\mathrm{CuIn}\left(\mathrm{Se}_{0.35} \mathrm{Te}_{0.65}\right)_{2}$, $\mathrm{CuIn}\left(\mathrm{Se}_{0.55} \mathrm{Te}_{0.45}\right)_{2}$ and $\mathrm{CuIn}\left(\mathrm{Se}_{0.62} \mathrm{Te}_{0.38}\right)_{2}$ with phase fractions $34 \%, 39 \%$ and $27 \%$, respectively. Refined values of lattice constants and the tetragonal distortion corresponding to these three phases are $a=6.05305(58) \AA, c=12.15750(186) \AA$ and distortion of 1.0037 for $x=0.35 ; a=5.97425(77) \AA$, $c=11.99530(256) \AA$ and distortion of 0.9967 for $x=0.55$; $a=5.93152(30) \AA, c=11.89101(136) \AA$ and distortion of 0.9961 for $x=0.62$. It is interesting to note here that although the system with starting $x=0.5$ forms a heterogeneous mixture of three phases, all the individual phases are quaternaries. Lattice spacing and the relative intensity of some reflections along with Miller indices for all the phases are listed in Table 2. These values are obtained from the Rietveld analysis. Similarly, the detailed analysis of experimental diffraction data together with the results of Rietveld refinement of crystal structure showed that the samples with $x=0.2-0.9$ have exhibited multiple quaternary phases (space group $I \overline{4} 2 d$ ). For comprehensive comparison of all the results such as lattice parameters, tetragonal distortions, phase fractions, anion displacements and discrepancy parameters for all compositions, the results are summarized in Table 3, while bond lengths and bond angles are listed in Table 4. The following conclusions may be drawn from the results of structure refinements. Melt-quench synthesized $\mathrm{CuIn}\left(\mathrm{Se}_{x} \mathrm{Te}_{1-x}\right)_{2}$, where $x=0.1,0.2,0.4,0.6,0.8$ and 0.9 , has formed with more than one phase, the exception being $x=0.1$. A schematic representation of the observed phases is presented in Fig. 5.

All the individual phases are quaternary phases with chalcopyrite structure, and there are no other elemental/ binary/secondary phases. Replacing 10 at $\%$ of Te by Se in $\mathrm{CuInTe}_{2}$ gives a single phase, while the converse, replacing 10 at\% of $\mathrm{Se}$ by $\mathrm{Te}$ in $\mathrm{CuInSe}_{2}$, results in two phases. Samples with $x=0.2,0.4,0.8$ and 0.9 have shown two quaternary phases, while the remaining two with $x=0.5$ and 0.6 have shown the presence of three phases. Samples with two phases have exhibited a specific trend in the phase fractions. First, for a given starting composition, the $\mathrm{Se}$ contents of the two crystallized phases are not far away 


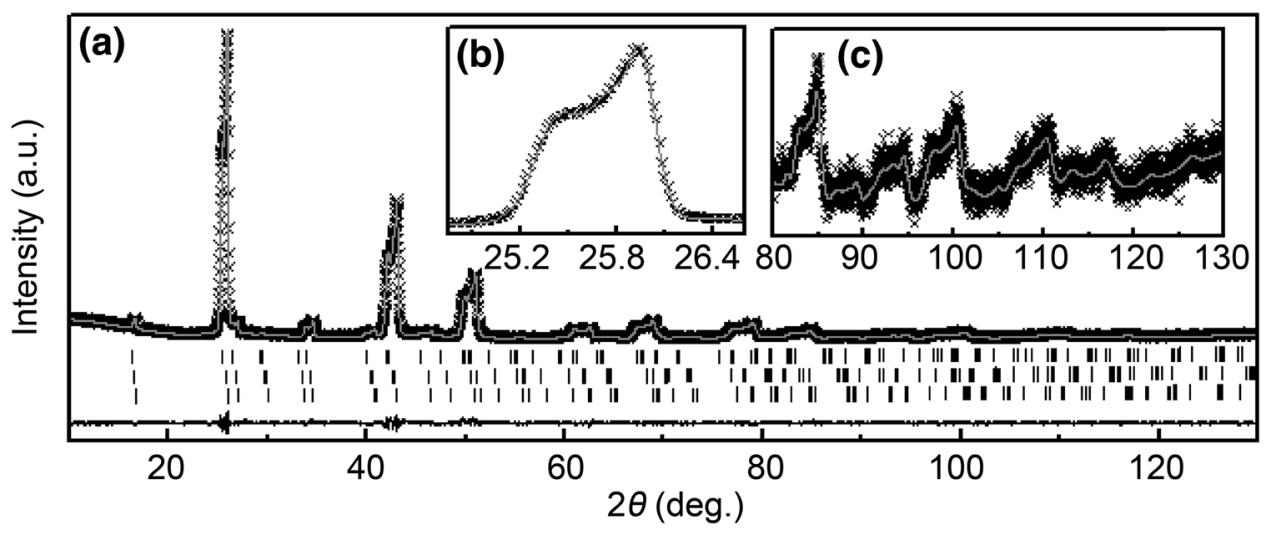

Fig. 4 a XRD pattern and the results of Rietveld refinement for $\mathrm{CuIn}\left(\mathrm{Se}_{0.5} \mathrm{Te}_{0.5}\right)_{2}$, the crosses and the overlying solid line represent the experimental data and the calculated profile, respectively, and the short vertical markers indicate possible Bragg reflections, whereas the bottom curve denotes the difference between the experimental and calculated data, $\mathbf{b}$ inset shows the enlarged view of 112 reflection, $\mathbf{c}$ inset shows the spectrum in the $2 \theta$ range of $80^{\circ}-130^{\circ}$, on an expanded scale

Table 2 Calculated lattice spacing $\left(d_{\text {cal }}\right)$, relative intensity $\left(I_{\text {cal }}\right)$ and Miller indices of selected reflections of $\mathrm{CuIn}\left(\mathrm{Se}_{0.35} \mathrm{Te}_{0.65}\right)_{2}$, CuIn($\left.\mathrm{Se}_{0.55} \mathrm{Te}_{0.45}\right)_{2}$ and $\mathrm{CuIn}\left(\mathrm{Se}_{0.62} \mathrm{Te}_{0.38}\right)_{2}$

\begin{tabular}{|c|c|c|c|c|c|c|}
\hline \multirow[t]{2}{*}{$h k l$} & \multicolumn{2}{|c|}{$\mathrm{CuIn}\left(\mathrm{Se}_{0.35} \mathrm{Te}_{0.65}\right)_{2}$} & \multicolumn{2}{|c|}{$\mathrm{CuIn}\left(\mathrm{Se}_{0.55} \mathrm{Te}_{0.45}\right)_{2}$} & \multicolumn{2}{|c|}{$\mathrm{CuIn}\left(\mathrm{Se}_{0.62} \mathrm{Te}_{0.38}\right)_{2}$} \\
\hline & $d_{\text {cal }}(\AA)$ & $I_{\text {cal }}(\%)$ & $d_{\text {cal }}(\AA)$ & $I_{\text {cal }}(\%)$ & $d_{\text {cal }}(\AA)$ & $I_{\text {cal }}(\%)$ \\
\hline 101 & 5.4186 & 0.6 & 5.3477 & 3.1 & 5.3078 & 1.1 \\
\hline 112 & 3.4997 & 90.7 & 3.4537 & 100.0 & 3.4273 & 68.6 \\
\hline 103 & 3.3675 & 3.9 & 3.3229 & 4.1 & 3.2956 & 3.3 \\
\hline 211 & 2.6423 & 6.5 & 2.6079 & 6.0 & 2.5890 & 4.9 \\
\hline 204 & 2.1446 & 21.7 & 2.1163 & 47.0 & 2.0996 & 32.3 \\
\hline 220 & 2.1401 & 20.3 & 2.1122 & 22.9 & 2.0971 & 15.5 \\
\hline 301 & 1.9905 & 3.4 & 1.9645 & 2.3 & 1.9504 & 1.5 \\
\hline 116 & 1.8314 & 14.2 & 1.8071 & 14.4 & 1.7919 & 9.9 \\
\hline 312 & 1.8258 & 24.2 & 1.8019 & 27.8 & 1.7888 & 18.0 \\
\hline 323 & 1.5510 & 3.0 & 1.5307 & 2.5 & 1.5194 & 1.8 \\
\hline 008 & 1.5197 & 3.5 & 1.4994 & 3.4 & 1.4864 & 2.3 \\
\hline 400 & 1.5133 & 5.3 & 1.4936 & 6.4 & 1.4829 & 4.0 \\
\hline 316 & 1.3915 & 9.3 & 1.3731 & 9.7 & 1.3623 & 6.7 \\
\hline 332 & 1.3890 & 3.9 & 1.3709 & 4.7 & 1.3610 & 3.0 \\
\hline 325 & 1.3815 & 1.6 & 1.3633 & 1.8 & 1.3530 & 1.2 \\
\hline 228 & 1.2391 & 5.9 & 1.2227 & 6.2 & 1.2127 & 3.9 \\
\hline 424 & 1.2364 & 9.3 & 1.2203 & 11.7 & 1.2112 & 6.8 \\
\hline 512 & 1.1651 & 3.3 & 1.1499 & 4.8 & 1.1416 & 2.9 \\
\hline 512 & 1.1651 & 3.3 & 1.1499 & 4.8 & 1.1416 & 2.9 \\
\hline
\end{tabular}

from the intended composition. Second, the phase fraction of the sample with lower Se content always has the larger phase fraction. These points can be illustrated more clearly by considering a specific case. For example, the sample grown with initial Se content of $x=0.2$ exhibits phases $\mathrm{CuIn}\left(\mathrm{Se}_{0.18} \mathrm{Te}_{0.82}\right)_{2}$ and $\mathrm{CuIn}\left(\mathrm{Se}_{0.25} \mathrm{Te}_{0.75}\right)_{2}$ with phase fractions of $67 \%$ and $33 \%$, respectively.
Average bond lengths, $\mathrm{Cu}-\mathrm{Se} / \mathrm{Cu}-\mathrm{Te}$ and $\mathrm{In}-\mathrm{Se} / \mathrm{In}-\mathrm{Te}$, decrease with Se content, but there are large fluctuation in the values. As expected, the average values of bond lengths decrease with Se content, but the fluctuations are quite small. Further, the average $\mathrm{Cu}-\mathrm{Se} / \mathrm{Cu}-\mathrm{Te}$ bond angle is larger than the In-Se/In-Te bond angles, which is also expected. These angles deviate considerably $\left(\sim 8^{\circ}\right)$ from the ideal value of $109.47^{\circ}$. The lattice constants $a$ and $c$ decrease linearly with Se content, with the tetragonal distortion close to one. The variation of the lattice constants with Se content are shown in Fig. 6.

\subsection{Phase Formation in $\mathrm{CuIn}\left(\mathrm{Se}_{x} \mathrm{Te}_{1-x}\right)_{2}$}

Phase formation in multi-element systems which are obtained from melt depends on both equilibrium phase diagram and cooling rate. If the cooing rate is high, the time for the system to establish thermodynamic equilibrium at successive stages is insufficient. This type of cooling is termed as non-equilibrium cooling and may lead to segregation of metastable phases. Therefore, non-equilibrium cooling is usually followed by thermal annealing at suitable temperatures for prolonged time to aid the formation of equilibrium phase [23, 24]. Solid solutions among different chalcopyrite compounds have been studied widely, and almost all the studies have been confined to the growth of equilibrium phases by following slow cooling or cooling followed by suitable thermal treatments. A detailed survey of reports on cation and anion-substituted solid solutions among the silver- and copper-based sulphides, and selenides [9, 13-16, 25-31] may pave the way to understand the physics and chemistry of phase formation. The earlier reports show that complete solubility is possible in all these 
Table 3 Selenium content, phase fraction, lattice parameters and discrepancy factors of $\mathrm{CuIn}\left(\mathrm{Se}_{x} \mathrm{Te}_{1-x}\right)_{2}$ system

\begin{tabular}{|c|c|c|c|c|c|c|c|c|}
\hline $\begin{array}{l}\text { Initial Se } \\
\text { content }(x)\end{array}$ & $\begin{array}{l}\text { Number of } \\
\text { phases }\end{array}$ & $\begin{array}{l}\text { Se content }(x) \text { in } \\
\text { individual phase }\end{array}$ & $\begin{array}{l}\text { Phase } \\
\text { fraction }(\%)\end{array}$ & $a(\AA)$ & $c(\AA)$ & $\begin{array}{l}\text { Tetragonal } \\
\text { distortion }(c / 2 a)\end{array}$ & $\begin{array}{l}R_{\mathrm{wp}} \\
(\%)\end{array}$ & $\overline{\text { GOF }}$ \\
\hline 0.1 & 1 & 0.10 & 100 & $6.15703(26)$ & $12.34222(65)$ & 0.99772 & 5.19 & 2.983 \\
\hline \multirow[t]{2}{*}{0.2} & \multirow[t]{2}{*}{2} & 0.18 & 67 & $6.12237(73)$ & $12.27821(190)$ & 0.99727 & \multirow[t]{2}{*}{7.82} & \multirow[t]{2}{*}{1.003} \\
\hline & & 0.25 & 33 & $6.09521(71)$ & $12.21471(209)$ & 0.99801 & & \\
\hline \multirow[t]{2}{*}{0.4} & \multirow[t]{2}{*}{2} & 0.33 & 52 & $6.06921(44)$ & $12.18564(150)$ & 0.99612 & \multirow[t]{2}{*}{4.83} & \multirow[t]{2}{*}{1.483} \\
\hline & & 0.49 & 48 & $5.99396(34)$ & $12.02776(146)$ & 0.99577 & & \\
\hline \multirow[t]{3}{*}{0.5} & \multirow[t]{3}{*}{3} & 0.35 & 34 & $6.05305(58)$ & $12.15750(186)$ & 1.00366 & \multirow[t]{3}{*}{3.89} & \multirow[t]{3}{*}{1.070} \\
\hline & & 0.55 & 39 & $5.97425(77)$ & $11.99530(256)$ & 0.99669 & & \\
\hline & & 0.62 & 27 & $5.93152(30)$ & $11.89101(136)$ & 0.99610 & & \\
\hline \multirow[t]{3}{*}{0.6} & \multirow[t]{3}{*}{3} & 0.40 & 39 & $6.03299(224)$ & $12.02198(977)$ & 0.99765 & \multirow[t]{3}{*}{6.92} & \multirow[t]{3}{*}{1.003} \\
\hline & & 0.68 & 26 & $5.91551(104)$ & $11.89604(406)$ & 0.99453 & & \\
\hline & & 0.74 & 35 & $5.88897(25)$ & $11.83534(108)$ & 0.99515 & & \\
\hline \multirow[t]{2}{*}{0.8} & \multirow[t]{2}{*}{2} & 0.77 & 62 & $5.88152(53)$ & $11.88444(180)$ & 0.98978 & \multirow[t]{2}{*}{4.19} & \multirow[t]{2}{*}{1.573} \\
\hline & & 0.83 & 38 & $5.83357(15)$ & $11.72506(65)$ & 0.99506 & & \\
\hline \multirow[t]{2}{*}{0.9} & \multirow[t]{2}{*}{2} & 0.87 & 67 & $5.83236(37)$ & $11.74639(122)$ & 0.99305 & \multirow[t]{2}{*}{5.37} & \multirow[t]{2}{*}{1.340} \\
\hline & & 0.95 & 33 & $5.80642(9)$ & $11.66750(40)$ & 0.99532 & & \\
\hline
\end{tabular}

solid solutions under different growth conditions, except in $\mathrm{CuInS}_{p} \mathrm{Te}_{1-p}$, where the miscibility is confined to $0<p<0.1$ and $0.93<p<1$, narrow regions close to the parent compounds. Though the procedure followed for preparing all these solid solution is found to be similar, synthesis temperature, annealing temperature and annealing duration vary with constituent elements [15, 31]. Long duration of annealing in specific cases is needed to stabilize the equilibrium phase, particularly in anion-substituted systems. It is necessitated due to the large difference in the ionic radii of anions.

At this stage, it is noteworthy to refer the high-temperature equilibrium phase diagrams of $\mathrm{CuInTe}_{2}-\mathrm{CuInSe}_{2}$ to understand the phase formation in $\mathrm{CuIn}\left(\mathrm{Se}_{x} \mathrm{Te}_{1-x}\right)_{2}[30$, $32,33]$. The data reported in these studies have good agreement in the general predictions on the nature of the phase diagram and the different phases present. But there are considerable differences in the actual temperatures at which the phase transformations occur. For discussions, the data reported by Bodnar et al. [32] have been considered, as it has also been referred in a more recent study [12]. Figure 7 shows the phase diagram of $\mathrm{CuInTe}_{2}-\mathrm{CuInSe}_{2}$ reported by Bodnar et al. [32], which is reproduced here for the sake of understanding of phase formation in the present case. As can be seen from Fig. 7, it is uncomplicated and it resembles that of a simple two-element isomorphous phase diagram, which is obtained when the two elements have complete solid and liquid miscibility in the entire range. To proceed further, the vertical line with nine points marked by horizontal ticks, and having a downward pointing arrow at one end, may be considered. Moving down the line essentially means cooling with fixed Se content, as the line lie on the Se content of $x=0.6$. The top most point lies beyond about $1100 \mathrm{~K}$. Clearly, at this point, only liquid phase with $x=0.6$ exists. As one moves down the line, no changes (composition or structure) occur until the second point is reached. The second point from top is on the liquidus line, where the liquid has $x=0.6$ and a solid phase starts to form. The composition of the solid phase can be readily calculated by drawing the tie line, a line that passes through point two and parallel to the horizontal axis (essentially an isotherm). The third point from top lies in between the liquidus and solidus line; both liquid and solid phases are present, however, with different Se contents and phase fractions. Their composition and phase fraction can again be calculated by drawing the tie line. This solid phase, however, has cubic zinc blende crystal structure, which is different from the equilibrium chalcopyrite structure. In fact, the end components themselves exhibit this hightemperature cubic phase, which may be understood from the pseudo-binary phase diagrams $\mathrm{Cu}_{2} \mathrm{Te}-\mathrm{In}_{2} \mathrm{Te}_{3}$ and $\mathrm{Cu}_{2} \mathrm{Te}-\mathrm{In}_{2} \mathrm{Se}_{3}$ [33]. For CuInTe 2 , as the temperature is increased, a solid-to-solid phase transition takes place at $945 \mathrm{~K}$. Beyond this temperature, the chalcopyrite structure changes to cubic zinc blende structure, wherein the I and III group atoms are randomly distributed in the cation sublattice. The cubic phase eventually melts congruently at $1062 \mathrm{~K}$. For CuInSe $\mathrm{C}_{2}$, the solid-state phase change from chalcopyrite to cubic structure takes place at $1083 \mathrm{~K}$ and the cubic phase melts congruently at $1259 \mathrm{~K}$. Therefore, it is possible that $\mathrm{CuInSe}_{2}-\mathrm{CuInTe}_{2}$ exhibit similar characteristics. 
Table 4 Anion displacement, bond length and bond angle of $\mathrm{CuIn}\left(\mathrm{Se}_{x} \mathrm{Te}_{1-x}\right)_{2}$ system

\begin{tabular}{|c|c|c|c|c|c|c|c|c|}
\hline \multirow{2}{*}{$\begin{array}{l}\text { Se content } \\
(x)\end{array}$} & \multirow{2}{*}{$\begin{array}{l}\text { Anion } \\
\text { displacement } \\
(\mu \mathrm{m})\end{array}$} & \multicolumn{4}{|c|}{ Bond length $(\AA)$} & \multicolumn{3}{|l|}{ Bond angle $\left({ }^{\circ}\right)$} \\
\hline & & $d_{(\mathrm{Cu}-\mathrm{Se} / \mathrm{Te})}$ & $d_{(\mathrm{In}-\mathrm{Se} / \mathrm{Te})}$ & $\mathrm{Cu}-\mathrm{Se} / \mathrm{Te}-\mathrm{Cu}$ & $\mathrm{In}-\mathrm{Se} / \mathrm{Te}-\mathrm{In}$ & $\mathrm{Se} / \mathrm{Te}-\mathrm{Cu}-\mathrm{Se} / \mathrm{Te}$ & $\mathrm{Se} / \mathrm{Te}-\mathrm{In}-\mathrm{Se} / \mathrm{Te}$ & $\mathrm{Cu}-\mathrm{Se} / \mathrm{Te}-\mathrm{In}$ \\
\hline \multirow[t]{2}{*}{0.10} & $0.22393(30)$ & $2.5788(10)$ & $2.7638(11)$ & $115.36(7)$ & $104.09(6)$ & 106.511(33) & $108.155(16)$ & $109.104(7)$ \\
\hline & & & & & & 110.971(17) & $112.136(32)$ & 109.289(16) \\
\hline \multirow[t]{2}{*}{0.18} & $0.2237(4)$ & $2.5638(14)$ & $2.7497(16)$ & $115.44(9)$ & $104.05(8)$ & $106.46(5)$ & $108.152(22)$ & 109.075(13) \\
\hline & & & & & & $110.999(24)$ & $112.14(4)$ & $109.296(9)$ \\
\hline \multirow[t]{2}{*}{0.25} & $0.2238(4)$ & $2.5521(14)$ & $2.7365(16)$ & $115.39(9)$ & $104.05(8)$ & 106.51(5) & $108.139(22)$ & 109.117(14) \\
\hline & & & & & & $110.973(24)$ & $112.17(4)$ & 109.277(10) \\
\hline \multirow[t]{2}{*}{0.33} & $0.21436(29)$ & $2.5130(9)$ & $2.7618(11)$ & 117.64(7) & $102.24(6)$ & 105.378(32) & $107.709(15)$ & 108.807(11) \\
\hline & & & & & & $111.556(17)$ & $113.057(31)$ & $109.121(8)$ \\
\hline \multirow[t]{2}{*}{0.35} & $0.21188(25)$ & $2.4989(8)$ & $2.7642(10)$ & $118.24(6)$ & $101.76(5)$ & 105.088(29) & $107.593(13)$ & 108.723(14) \\
\hline & & & & & & $111.706(15)$ & $113.298(27)$ & $109.065(8)$ \\
\hline \multirow[t]{2}{*}{0.40} & $0.2217(4)$ & $2.5143(17)$ & $2.7115(19)$ & $115.73(10)$ & 103.48(9) & $106.59(7)$ & 107.887(32) & 109.084(26) \\
\hline & & & & & & $110.930(35)$ & $112.69(7)$ & $109.38(5)$ \\
\hline \multirow[t]{2}{*}{0.49} & $0.22873(29)$ & $2.5270(9)$ & $2.6739(11)$ & $114.28(7)$ & 105.10(6) & 106.979(32) & 108.431(15) & $109.130(8)$ \\
\hline & & & & & & 110.731(16) & $111.573(31)$ & 109.398(16) \\
\hline \multirow[t]{2}{*}{0.55} & $0.23241(25)$ & $2.5312(9)$ & $2.6523(9)$ & $113.46(6)$ & $105.87(5)$ & 107.348(30) & $108.638(14)$ & 109.149(14) \\
\hline & & & & & & $110.543(15)$ & $111.150(29)$ & $109.466(7)$ \\
\hline \multirow[t]{2}{*}{0.62} & $0.21928(25)$ & $2.4698(8)$ & $2.6797(9)$ & 116.44(6) & 103.17(5) & 106.000(28) & 107.919(13) & 109.196(6) \\
\hline & & & & & & 111.234(14) & $112.623(27)$ & 109.006(9) \\
\hline \multirow{2}{*}{0.68} & $0.2257(4)$ & $2.4863(14)$ & $2.6515(16)$ & $115.03(10)$ & $104.55(9)$ & 106.53(5) & $108.332(24)$ & $108.965(22)$ \\
\hline & & & & & & $110.960(26)$ & $111.77(5)$ & 109.408(13) \\
\hline \multirow[t]{2}{*}{0.74} & $0.2337(4)$ & $2.5002(14)$ & $2.6105(15)$ & $113.19(10)$ & 106.17(9) & 107.44(5) & 108.734(23) & $109.114(7)$ \\
\hline & & & & & & $110.495(24)$ & $110.96(5)$ & 109.508(6) \\
\hline \multirow[t]{2}{*}{0.77} & $0.21566(27)$ & $2.4449(8)$ & $2.6769(10)$ & $117.50(6)$ & 102.67(5) & 105.167(31) & 107.937(14) & 109.327(8) \\
\hline & & & & & & $111.665(16)$ & $112.585(30)$ & 108.497(12) \\
\hline \multirow[t]{2}{*}{0.83} & $0.23797(27)$ & $2.4904(9)$ & $2.5713(9)$ & $112.25(6)$ & $107.05(6)$ & 110.264(15) & $110.500(29)$ & $109.553(3)$ \\
\hline & & & & & & 107.897(30) & 108.959(14) & $109.152(4)$ \\
\hline \multirow[t]{2}{*}{0.87} & $0.2357040(0)$ & $2.48430(14)$ & $2.58032(14)$ & $112.805(3)$ & 106.633(3) & $110.446(3)$ & $110.634(7)$ & 109.587(3) \\
\hline & & & & & & $107.540(7)$ & 108.893(3) & 109.021(7) \\
\hline \multirow[t]{2}{*}{0.95} & $0.2285370(0)$ & $2.44849(4)$ & $2.59204(4)$ & $114.366(1)$ & $105.095(1)$ & $110.781(1)$ & $111.520(2)$ & $109.433(1)$ \\
\hline & & & & & & $106.882(2)$ & 108.457(1) & $109.053(2)$ \\
\hline
\end{tabular}

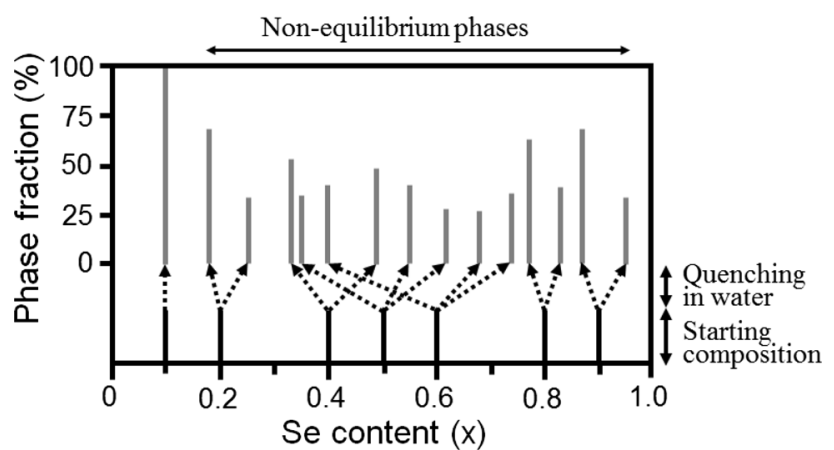

Fig. 5 Schematic of phase formation in $\mathrm{CuIn}\left(\mathrm{Se}_{x} \mathrm{Te}_{1-x}\right)_{2}$. Dark vertical lines are just markers. Grey vertical lines represent percentage (lengthwise) of the phases

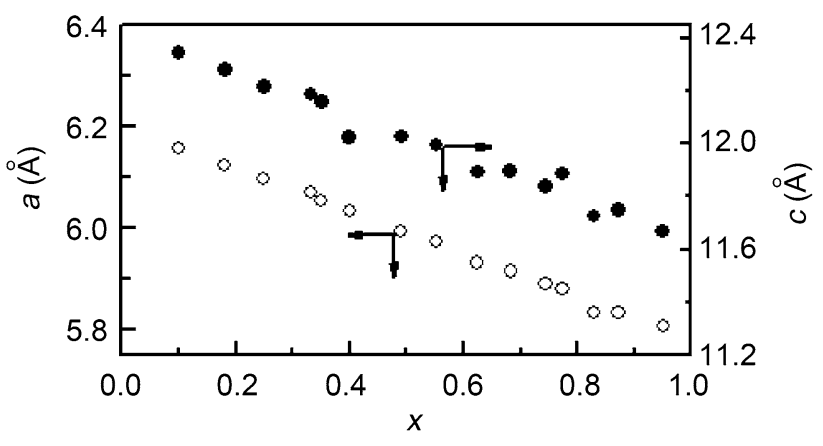

Fig. 6 Variation of lattice parameters with selenium content $(X)$. Open circles denote ' $a$ ' whereas solid circles represent ' $c$ ' 


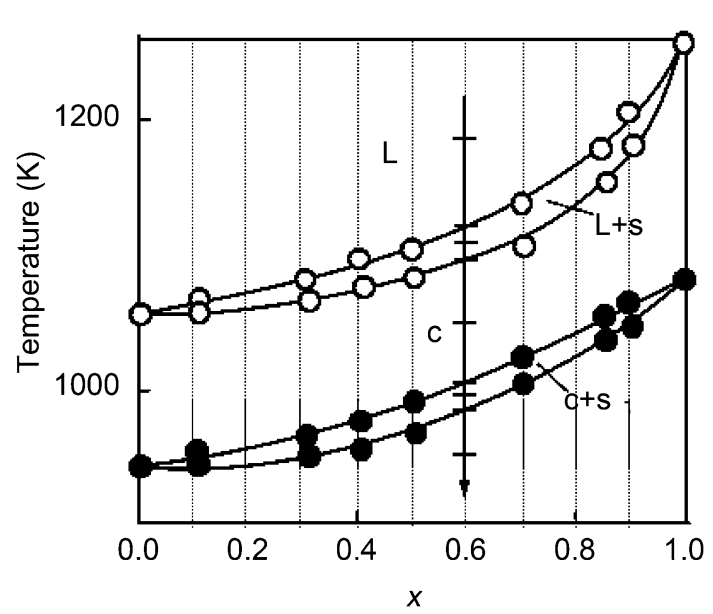

Fig. $7 \mathrm{CuInSe}_{2}-\mathrm{CuInTe}_{2}\left(\mathrm{CuIn}\left(\mathrm{Se}_{x} \mathrm{Te}_{1-x}\right)_{2}\right)$ phase diagram reproduced from Bodnar et al. [32]

Coming back to the "isomorphic" $\mathrm{CuInSe}_{2}-\mathrm{CuInTe}_{2}$ phase diagram, the discussion on the phase with Se content of $x=0.6$ can be continued further by considering the fourth point from top that lies on the solidus curve. While between points four and six from top (for instance, the fifth point), the sample has the cubic structure, and another crystalline phase starts precipitating at the sixth point from top. This second solid phase is the equilibrium chalcopyrite phase. At point seven from top, both solid phases are present, and as the eighth point from top is approached, the phase fraction of the chalcopyrite phase continues to grow and the transformation is almost complete at this point. At anywhere below this point along the vertical line (e.g. the last point), chalcopyrite phase alone prevails, indicating that no other compositional/phase change can take place. It must be recalled again that the composition (Se content) and the phase fractions can be calculated by drawing the tie line. It should also be noted that when moving down the line (during cooling), different phases with different phase fractions may form. However, the overall composition will be preserved with redistribution of Se and Te among the phases. Thus, it can be concluded that for any Se content, the chalcopyrite structure has the lowest energy configuration. It is also important to note that the above discussions have been based on equilibrium phase diagram. Therefore, a sample with a given Se content will crystallize with the chosen composition, provided it is cooled at a sufficiently low rate from the melt.

In the present case, the cooling rate is of the order of $10^{2} \mathrm{~K} / \mathrm{s}$. For the end compounds, $\left(\mathrm{CuInTe}_{2}\right.$ and $\left.\mathrm{CuInSe}_{2}\right)$ solidification, i.e. transformation from liquid to solid phase is independent of the rate of cooling, since both melt congruently. This is to be contrasted with incongruent transformation, which depends on cooling rate as the dominant factor is inter-diffusion of the species. For the sample with $x=0.1$, the cooling rate seems to be low as it crystallizes with the equilibrium chalcopyrite structure when quenched from melt. On the other hand, for the rest of the solid solutions considered, the cooling appears to be fast, as they crystallize with more than one phase. In other words, the cooling rate used in the present experiments falls in the non-equilibrium cooling category for samples with initial Se content of $x=0.2,0.4,0.5,0.6,0.8$ and 0.9.

When the cooling rate is too high, equilibrium composition will not prevail (non-equilibrium cooling) and phases with different Se content may segregate. This is because change in temperature leads to the formation of different phases (liquid and crystalline phases) with different $\mathrm{Se}$ content and phase fractions. All these changes must take place in consistent with the equilibrium phase diagram. These changes require redistribution of the constituent elements which proceeds through diffusion-controlled process. Since diffusion is kinetically driven, equilibrium configuration at successive steps cannot be reached at infinitely large rate. Rather it happens over finite timescales. Moreover, diffusion rate of a particular species is not same in liquid or solid or across liquid-solid interface. Furthermore, the large difference in the ionic radii of $\mathrm{Se}$ and $\mathrm{Te}$ will have a bearing as well, on the time required to reach equilibrium. All these factors govern the time needed to reach equilibrium. Thus, when the time taken to reach the equilibrium configuration is longer compared to the cooling rate, intermediate non-equilibrium phases or secondary phases can form. But all the crystallized phases will be quaternaries with chalcopyrite structure as observed in the present work, which is consistent with what has been predicted by the $\mathrm{CuInTe}_{2}-\mathrm{CuInSe}_{2}$ equilibrium phase diagram.

\subsection{Raman Spectroscopy}

The Raman spectra of bulk $\mathrm{CuIn}\left(\mathrm{Se}_{x} \mathrm{Te}_{1-x}\right)_{2}$ with $x=0.1$ and 0.5 are shown in Fig. 8a and b, respectively, as representative spectra of all samples. In figures, open circles represent the experimental data points, grey lines show the individual Lorentzians, and the black line through open circles denotes the overall fit. The peak positions obtained from deconvolution of individual spectrum are 127.2, $130.6,133.4,146.2,155.1,162.7,171.4,175.7,175.7$, $180.5,184.6$ and $198.3 \mathrm{~cm}^{-1}$ for $x=0.1$ and 127.4, 134.9, 143.7, 149.3, 154.0, 161.1, 175.0, 182.6, 192.1, 200.1, 207.4 and $215.4 \mathrm{~cm}^{-1}$ for $x=0.5$. Raman spectra of anion-substituted I-III- $-\mathrm{VI}_{2}$ solid solutions are expected to show features similar to those of their parent compounds. This is because the solid solutions obtained by anion substitution usually crystallize in space group $I \overline{4} 2 d$ and point group $\overline{4} 2 m$ with eight atoms per primitive unit cell. 

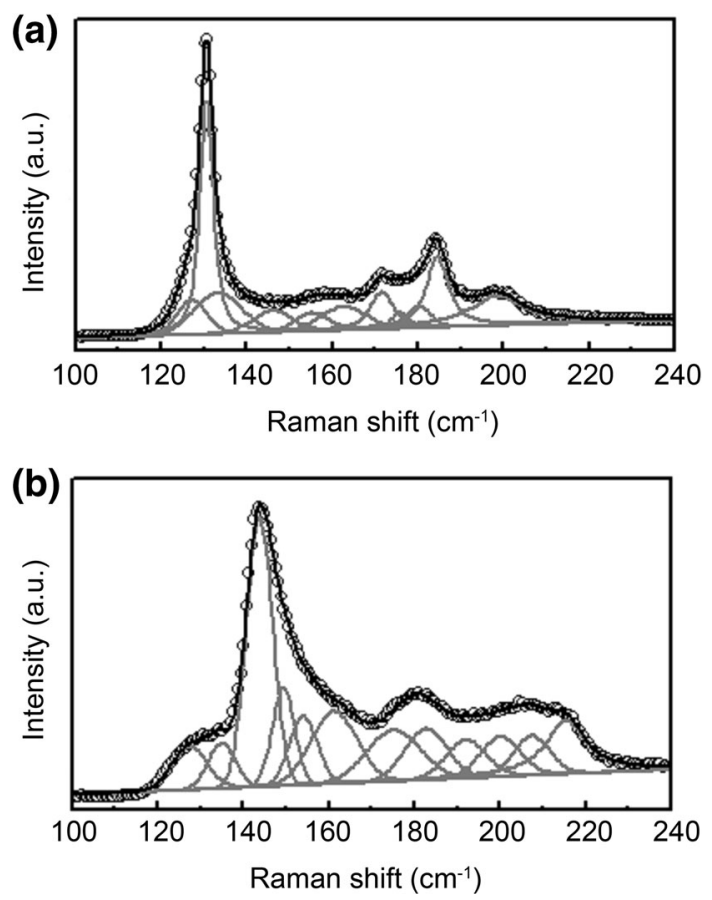

Fig. 8 Raman spectra of a $\mathrm{CuIn}\left(\mathrm{Se}_{0.1} \mathrm{Te}_{0.9}\right)_{2}$ and $\mathbf{b} \mathrm{CuIn}\left(\mathrm{Se}_{0.5} \mathrm{Te}_{0.5}\right)_{2}$, the symbols, lines and dark line show the experimental data, individual Lorentzians and the overall fit, respectively

Therefore, Raman spectra of $\mathrm{CuIn}\left(\mathrm{Se}_{x} \mathrm{Te}_{1-x}\right)_{2}$ system can be analysed by adopting the procedure that has been followed for I-III-VI 2 compounds. Group theoretical calculations for the chalcopyrite system are reported in the literature [34]. The results have shown that at the Brillouin zone centre $(q=0)$, the irreducible representation for optical modes can be written as $1 A_{1} \oplus 3 B_{1} \oplus 3 B_{2} \oplus 6 E$. Among these, $B_{2}$ and $E$ are doubly degenerate and they are both Raman and infrared active. Further, $B_{2}$ and $E$ modes can be subdivided into longitudinal and transverse optical modes due to their polar character. Thus, there are 12 $E$ modes, $6 B_{2}$ modes, $3 B_{1}$ modes and a single $A_{1}$ mode, leading to a total of 22 modes.

First principle lattice dynamical calculations have not been performed for chalcopyrites. However, two main simplified models viz. tetra-atomic linear chain model [35] and simplified Keating model [36] are available, using which Raman shifts of certain modes can be calculated. Though there is some ambiguity in mode assignment in tetra-atomic linear chain model, the expression for $A_{1}$ mode is same in both the models. In the present work, the simplified Keating model has been followed to estimate the Raman shit of $A_{1}$ mode. The Keating model [37] considers two important parameters; the first is the force constant that accounts for the stretching of bond between an atom and its first nearest neighbour and the second is the force constant that accounts for the bond-bending motion. The latter is a three-body interaction and is essentially an angular interaction. Further, the tetragonal distortion is neglected in the Keating model. In the simplified Keating model, the bond-bending force constants are not considered, in addition. This allows simplification of the dynamical matrix to obtain expressions for few of the modes, so that estimation of the same can be made. It is important at this stage to note that in the simplified Keating model, the expressions for certain modes come out to be same and also the Raman shift of some of the modes will become zero [36].

Among the 22 Raman active modes, $A_{1}$ mode has the highest intensity and is recognized as the characteristic mode of chalcopyrite structure. Therefore, $A_{1}$ mode has been studied in detail to begin with. Results of Rietveld refinements revealed that the anion sub-lattice in the unit cell of $\mathrm{CuIn}\left(\mathrm{Se}_{x} \mathrm{Te}_{1-x}\right)_{2}$ is statistically shared by both $\mathrm{Se}$ and $\mathrm{Te}$ atoms. This kind of sharing leads to two different types of basic tetrahedral arrangements: one with $\mathrm{Se}$ as the central atom and the other with $\mathrm{Te}$ as the central atom. In both tetrahedrons, the central atom is bonded to two $\mathrm{Cu}$ and two In atoms. This should be contrasted with the basic tetrahedral unit of chalcopyrite lattice, wherein the two group I atoms and the two group III atoms are bonded to only one type of group VI atom. The basic tetrahedral units in the parent compounds and the solid solutions obtained by replacing Te by $\mathrm{Se}$ are depicted in Fig. 9. The above discussion suggested that the expression given by Neumman [36] cannot be used directly. It requires modification, as two different atoms ( $\mathrm{Te}$ and $\mathrm{Se}$ ) have to be accommodated in the anion sub-lattice. This can be accomplished as

$\omega^{2}\left(A_{1}\right)=\left[2\left(\alpha_{A}+\alpha_{B}\right) /\left(x M_{\mathrm{Se}}+(1-x) M_{\mathrm{Te}}\right)\right]$,

where $\alpha_{A}$ and $\alpha_{B}$ average force constants of $\mathrm{Cu}-\mathrm{Se} / \mathrm{Te}$ and In-Se/Te bonds, respectively, and $\omega^{2}$ is the Raman shift. $M_{\mathrm{Te}}$ and $M_{\mathrm{Se}}$ are, respectively, the atomic mass of Te and Se atoms. The force constants $\left(\alpha_{A}\right.$ and $\left.\alpha_{B}\right)$ can be related to the average bond lengths as $\alpha_{A}=0.037\left(19.67 / d_{A}\right)^{3.255}$ and $\alpha_{B}=0.145\left(15.91 / d_{B}\right)^{3.105}$ [38], where $d_{A}$ and $d_{B}$ are, respectively, the average bond lengths of $\mathrm{Cu}-\mathrm{Se} / \mathrm{Te}$ and In$\mathrm{Se} / \mathrm{Te}$ bonds, obtained from the Rietveld analysis. A similar analysis has been reported [39] in the studies on dependence of Raman shift on the composition of the anions in $\mathrm{CuGaSe}_{2}$. Specifically, the force constants have been written as a weighted sum, determined by the ratio of $\mathrm{Cu}$ and $\mathrm{Ga}$ content. Figure 10 shows the variation of Raman shift of the $A_{1}$ mode for the individual phase with different Se content in all samples. In Fig. 10, the open circles denote the observed data while the plus marks represent the calculated data. The continuous line shows the linear fit to the observed data. The calculated values were obtained by calculating the force constants $\alpha_{A}$ and $\alpha_{B}$ using the respective $d$ values obtained from Rietveld analysis and then substituting them in Eq. (1). As seen from Fig. 10, the calculated values are close to the experimental 


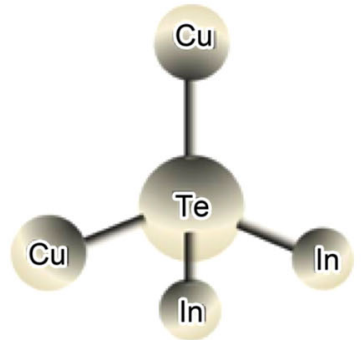

(a)

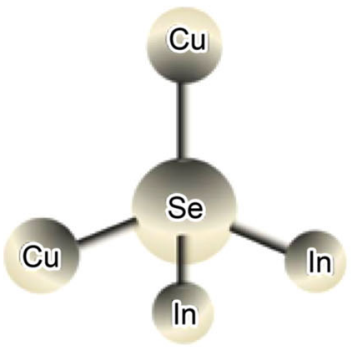

(b)

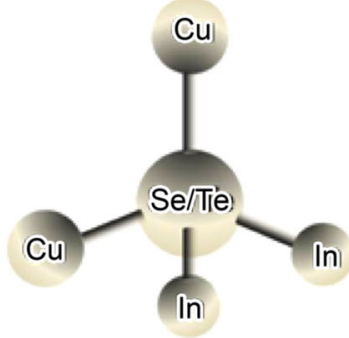

(c)

Fig. 9 Basic tetrahedral in a CuInTe $e_{2}$-like, b CuInSe $e_{2}$-like and $\mathbf{c}$ with statistical distribution of $\mathrm{Te}$ and $\mathrm{Se}$ atoms in $\left.\mathrm{CuIn}_{(\mathrm{Se}} \mathrm{Se}_{1-x}\right)_{2}$

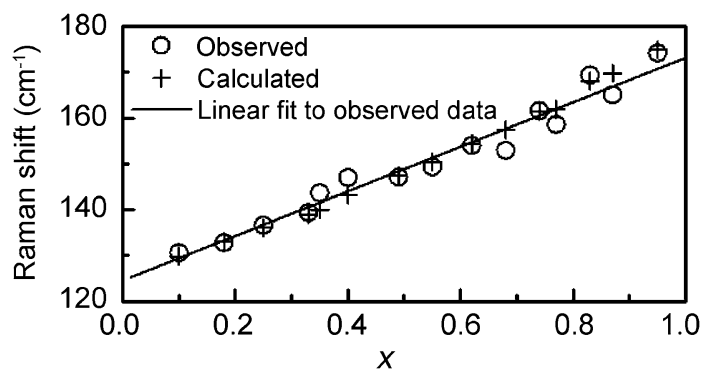

Fig. 10 Results of $A_{1}$ mode analysis for $\operatorname{CuIn}\left(\operatorname{Se}_{x} \mathrm{Te}_{1-x}\right)_{2}$, the average force constants for the calculations are taken from the results of the Rietveld refinement

Table 5 Observed and calculated Raman shift for the $A_{1}$ mode for different phases, denoted by Se content $(x)$

\begin{tabular}{lllc}
\hline \multirow{2}{*}{ Selenium content $(x)$} & \multicolumn{2}{l}{ Raman shift $\left(\mathrm{cm}^{-1}\right)$} & FWHM $\left(\mathrm{cm}^{-1}\right)$ \\
\cline { 2 - 3 } & Observed & Calculated & \\
\hline 0.10 & 130.6 & 129.8 & 3.8 \\
0.18 & 132.8 & 133.0 & 4.8 \\
0.25 & 136.6 & 136.0 & 13.5 \\
0.33 & 139.3 & 138.9 & 6.7 \\
0.35 & 143.7 & 140.0 & 7.2 \\
0.40 & 147.0 & 143.2 & 6.8 \\
0.49 & 147.1 & 147.4 & 11.1 \\
0.55 & 149.3 & 150.4 & 6.2 \\
0.62 & 154.0 & 154.4 & 7.8 \\
0.68 & 152.9 & 157.4 & 8.6 \\
0.74 & 161.6 & 161.4 & 12.3 \\
0.77 & 159.4 & 161.9 & 7.2 \\
0.83 & 165.4 & 168.1 & 7.1 \\
0.87 & 165.1 & 169.8 & 9.8 \\
0.95 & 174.2 & 174.9 & 9.8 \\
\hline
\end{tabular}

data. This corroborates the results of phase analysis by Rietveld refinement of the crystal structure well. The data obtained from the analysis are given in Table 5. Thus, as seen from Fig. 10, the $A_{1}$ mode varies linearly with $\mathrm{Se}$ content like the lattice constants. It is possible to calculate few more modes by suitably modifying the expressions given for other modes. However, this has not been attempted as the samples are heterogeneous with more than one phase. For instance, the sample with initial Se content of $x=0.5$ contained three different phases with a maximum of 22 modes for each, which rendered unique mode assignment untenable. Further, while the expressions obtained from simplified Keating model reproduce the modes of Te-based systems well, the same was difficult for Sebased systems. For instance, the Keating model yields a value of $178.7 \mathrm{~cm}^{-1}$ for the $A_{1}$ mode of $\mathrm{CuInSe}_{2}$, and the experimentally observed values are in the range $173-175 \mathrm{~cm}^{-1}$. Therefore, the analysis was confined to $A_{1}$ mode alone. Of course, as mentioned earlier the $A_{1}$ mode is considered as a unique signature of the chalcopyrite phase.

Raman studies pertaining to the solid solutions among the I-III- $-\mathrm{VI}_{2}$ chalcopyrite compounds are not many, while numerous reports are available on the theoretical and experimental analysis of Raman modes of I-III- $-\mathrm{VI}_{2}$ chalcopyrite compounds. The available reports include investigations on both cation- and anion-substituted systems. Interestingly, both systems have been found to display characteristics that are unique to them. The cationsubstituted systems exhibit single-mode behaviour, while the anion-substituted systems exhibit two-mode behaviour. Classification of mode behaviour into single mode and two-mode has originated from the vibrational mode behaviour of ternary solid solutions formed among the binary compounds from II-VI and III-V group semiconductors as well as alkali halides [40]. In case of single-mode behaviour, the solid solutions exhibit single compositiondependent mode that varies mostly linearly with composition. Consequently, Raman shift can be taken as a direct measure of the composition. In case of two-mode behaviour, there is no composition-dependent mode; rather two modes appear with Raman shifts close to those of the parent compounds. These are termed as "parent-like". Both need not exhibit Raman shift with composition; otherwise, the nature and magnitude of the shifts can differ. The relative intensities of the "parent-like" modes usually 
follow a specific pattern, from which the composition can be determined. Apart from these two, a third case of mixedmode behaviour has also been observed. In this type of mode, the spectra will have a complex structure and modes characteristic of composition appear, in addition to "parent-like" modes. Several theoretical studies and even some simple "rules" have been used to analyse/predict the existence of such mode behaviours [41], although with limited success. The calculations include those based on the well-known Random element isodisplacement model. The "rule" that is often used to predict the existence of singleor two- or mixed-mode behaviour is based on the relative masses of the three individual elements in the ternary solid solution $[41,42]$.

As discussed earlier, the solid solutions in chalcopyrite compounds show either single-mode [43-48] or two-mode $[43,49-51]$ behaviour depending on cation or anion substitution, respectively. For instance, in $\mathrm{CuIn}\left(\mathrm{S}_{p} \mathrm{Se}_{1-p}\right)_{2}$, Raman shift of CuInSe ${ }_{2}$-like $A_{1}$ mode varied linearly from 174 to $202 \mathrm{~cm}^{-1}$ in the range of $x=0-0.8$, while that of $\mathrm{CuInS}_{2}$-like $A_{1}$ mode showed linear shift from 295 to $287 \mathrm{~cm}^{-1}$ for $x=0.35-1$. Further, the relative intensity of $\mathrm{CuInS}_{2}$-like $A_{1}$ mode was found to increase with $\mathrm{S}$ content, while that of $\mathrm{CuInSe}_{2}$-like $A_{1}$ mode was found to increase with Se content, which is expected. Thus, the $A_{1}$ mode in $\mathrm{CuIn}\left(\mathrm{Se}_{x} \mathrm{Te}_{1-x}\right)_{2}$ system exhibits single-mode behaviour and is evident from the clear shift of the highest intensity peak, which varies linearly with Se content. This behaviour is in contrast to what is expected, as the literature reported so far suggests two-mode behaviour for solid solutions obtained by anion substitution. It is instructive to note here that no theoretical basis exists to account for the mode behaviour in solid solutions among chalcopyrite compounds and also the available data are not exhaustive either. In view of this, the present results may not be classified as unusual or exception. In fact, site-specific dependence (cation site or anion site) of mode behaviour has not been observed even in ternary solid solutions [52, 53].

An interesting observation in the Raman spectra of present study has been the presence of peaks at about 127 and $175 \mathrm{~cm}^{-1}$ where the modes of parent compounds are expected, in all the compositions except the last one with $x=0.9$. For the sample with $x=0.9$, the mode at $127 \mathrm{~cm}^{-1}$ is present, but the one at $175 \mathrm{~cm}^{-1}$ is not. The reason may be that it is too close to the composition-dependent mode, which appears at $174.2 \mathrm{~cm}^{-1}$. As far as the relative intensities are concerned, the intensity of the parent mode at $127 \mathrm{~cm}^{-1}$ is higher for the sample with starting Se content of $x=0.1$ than the intensity of the corresponding peak observed in the sample with starting Se content of $x=0.9$. The intensity variation of the parent mode at $174.2 \mathrm{~cm}^{-1}$ was quite the opposite. Its intensity is much lower in the sample with $x=0.1$ than that observed in the sample with $x=0.9$. This observation suggests a kind of multi-mode behaviour, but further studies, especially, on homogeneous crystals are needed to substantiate this behaviour. It should also be noted that detailed analysis of all the modes is required before the nature of mode behaviour in $\mathrm{CuIn}\left(\mathrm{Se}_{x} \mathrm{Te}_{1-x}\right)_{2}$ is commented.

\section{Conclusions}

Non-equilibrium phases formed in melt-quench synthesized powder samples of $\mathrm{CuIn}\left(\mathrm{Se}_{x} \mathrm{Te}_{1-x}\right)_{2}, x=0.1,0.2$, 0.4, 0.5, 0.6, 0.8 and 0.9, has been studied using Rietveld refinement of the crystal structure and Raman spectroscopy. The refinement results showed that all samples, except that with Se content of $x=0.1$, are heterogeneous. All the observed non-equilibrium phases are quaternary systems with chalcopyrite structure $(I \overline{4} 2 d)$. The lattice constants deduced from the refinement showed linear variation with Se content. A detailed analysis of the characteristic $A_{1}$ mode in the Raman spectra corroborated the results of phase analysis by XRD. The position of $A_{1}$ mode is found to vary linearly with Se content, which suggests that $\mathrm{CuIn}\left(\mathrm{Se}_{x} \mathrm{Te}_{1-x}\right)_{2}$ exhibits single-mode behaviour. Further studies, especially, on single crystals are required to substantiate the appearance of parent modes.

\section{References}

[1] S. Siebentritt, U. Rau (eds.), Wide-Gap Chalcopyrites (Springer, Berlin, 2006)

[2] P.Y. Yu, D.H.C.M. Cardona, Fundamentals of Semiconductors: Physics and Materials Properties (Springer, Berlin, 2010)

[3] D. Xue, K. Betzler, H. Hesse, Phys. Rev. B 62, 13546 (2000)

[4] D.N. Nikogosian, Nonlinear Optical Crystals: A Complete Survey (Springer, New York, 2005)

[5] P. Jackson, D. Hariskos, E. Lotter, S. Paetel, R. Wuerz, R. Menner, W. Wischmann, M. Powalla, Prog. Photovolt. 19, 894 (2011)

[6] S. Marsillac, P.D. Paulson, M.W. Haimbodi, R.W. Birkmire, W.N. Shafarman, Appl. Phys. Lett. 81, 1350 (2002)

[7] K. Yamada, N. Hoshino, T. Nakada, Sci. Technol. Adv. Mater. 7, 42 (2006)

[8] V. Izquierdo-Roca, X. Fontane, J. Alvarez-Garcia, L. CalvoBarrio, A. Perez-Rodriguez, J.R. Morante, C.M. Ruiz, E. Saucedo, V. Bermudez, Appl. Phys. Lett. 94, 061915 (2009)

[9] I.H. Choi, S.H. Eom, P.Y. Yu, J. Appl. Phys. 87, 3815 (2000)

[10] R. Diaz, M. Leon, F. Rueda, J. Vac. Sci. Technol. A 10, 295 (1992)

[11] R. Herberholz, M.J. Carter, Sol. Energy Mater. Sol. Cells 44, 357 (1996)

[12] I.V. Bodnar, N.P. Solovei, V.S. Gurin, A.P. Molochko, Semiconductors 38, 1402 (2004)

[13] B.R. Pamplin, T. Kiyosawa, K. Masumoto, Prog. Cryst. Growth Charact. Mater. 1, 331 (1979)

[14] J.E. Avon, K. Yoodee, J.C. Woolley, J. Appl. Phys. 55, 524 (1984) 
[15] S. Chatraphorn, T. Panmatarite, S. Pramatus, A. Prichavudhi, R. Kritayakirana, J. Berananda, V. Sa-yakanit, J.C. Woolley, J. Appl. Phys. 57, 1791 (1985)

[16] C.H. Champnes, J. Mater. Sci. Mater. Electron. 1, 605 (1999)

[17] A.C. Larson, R.B. Von Dreele, General Structure Analysis System (GSAS), (Report LAUR 86-748), Los Alamos National Laboratory, 2004

[18] G. Masse, K. Djessas, L. Yarzhou, J. Appl. Phys. 74, 1376 (1993)

[19] R.A. Young (ed.), The Rietveld Method (IUCr Monograph on Crystallography, No. 5) (Oxford University Press, New York, 1993)

[20] M. Leon, J.M. Merino, G. Van Tendeloo, Acta Microsc. 18, 128 (2009)

[21] N.F.M. Henry, K. Lonsdale (eds.), International Tables for $X$-Ray Crystallography, Vol. I. Symmetry Groups (The Kynoch Press, Birmingham, 1965)

[22] S.R. Hall, J.M. Stewart, Acta Crystallogr. Sect. B Struct. Sci. 29, 579 (1973)

[23] T.R. Anantharaman, C. Suryanarayana, J. Mater. Sci. 6, 1111 (1971)

[24] W.D. Callister Jr, Fundamental of Materials Science and Engineering (Wiley, New York, 2001)

[25] G.H. Chapman, J. Shewchun, J.J. Loferski, B.K. Garside, R. Beaulieu, Appl. Phys. Lett. 34, 735 (1979)

[26] J.E. Avon, J.C. Woolley, J. Appl. Phys. 52, 6423 (1981)

[27] B. Pamplin, R.S. Feigelson, Thin Solid Films 60, 141 (1979)

[28] M. Quintero, J.C. Woolley, J. Appl. Phys. 55, 2825 (1984)

[29] P. Grima, M. Quintero, C. Rincon, G.S. Peres, J.C. Woolley, Solid State Commun. 67, 81 (1988)

[30] M. Quintero, R. Tovar, E. Guerrero, F. Sanchez, J.C. Woolley, Phys. Status Solidi A 125, 161 (1991)

[31] L.P. Marushko, Y.E. Romanyuk, L.V. Piskach, O.V. Parasyuk, I.D. Olekseyuk, S.V. Volkov, V.I. Pekhnyo, Chem. Met. Alloys 3, $18(2010)$
[32] I.V. Bodnar, I.A. Zabelina, B.V. Korzun, A.P. Chernyakova, Zh Neorg, Khim. 36, 1062 (1991)

[33] L.S. Palatnik, E.I. Rogacheva, Sov. Phys. Dokl. 12, 503 (1967)

[34] I.P. Kaminow, E. Buehler, J.H. Wernick, Phys. Rev. B 2, 960 (1970)

[35] G.D. Holah, A.A. Schenk, S. Perkowitz, R.D. Tomlinson, Phys. Rev. B 23, 6288 (1981)

[36] H. Neumann, Helv. Phys. Acta 58, 337 (1985)

[37] P.N. Keating, Phys. Rev. 149, 674 (1966)

[38] V. Kumar, D. Chandra, Phys. Status Solidi B 212, 37 (1999)

[39] D. Papadimitriou, N. Esser, C. Xue, Phys. Status Solidi B 242, 2633 (2005)

[40] L. Genzel, W. Bauhofer, Z. Phys. B 25, 13 (1976)

[41] E. Oh, A.K. Ramdas, J. Electron. Mater. 23, 307 (1994)

[42] I.F. Chang, S.S. Mitra, Adv. Phys. 20, 359 (1971)

[43] H. Matsushita, S. Endo, T. Irie, Jpn. J. Appl. Phys. 31, 18 (1992)

[44] I.V. Bodnar, Semiconductors 32, 613 (1998)

[45] K. Takarabe, K. Kawai, K. Wakamura, S. Minomura, N. Yamamoto, J. Cryst. Growth 99, 766 (1990)

[46] I.V. Bodnar, J. Appl. Spectrosc. 66, 928 (1999)

[47] H. Tanino, H. Deai, H. Nakanishi, Jpn. J. Appl. Phys. 32, 436 (1993)

[48] Y. Cui, U.N. Roy, P. Bhattacharya, A. Parker, A. Burger, J.T. Goldstein, Solid State Commun. 150, 1686 (2010)

[49] I.V. Bodnar, G.F. Smirnova, A.G. Karoza, A.P. Chernyakova, Phys. Status Solidi B 158, 469 (1990)

[50] R. Bacewicz, W. Gebicki, J. Filipowicz, J. Phys. Condens. Matter 6, L777 (1994)

[51] S. Shirakata, T. Terasako, T. Kariya, J. Phys. Chem. Solids 66, 1970 (2005)

[52] A. Anastassiadou, E. Liarokapis, E. Anastassakis, Solid State Comm. 69, 137 (1989)

[53] L.A. Farrow, J.M. Worlock, F. Turco-Sandroff, R.E. Nahory, R. Beserman, D.M. Hwang, Phys. Rev. B 45, 1231 (1992) 